\title{
Pattern And Prevalence Of Rheumatic Heart Disease By Echocardiographic Evaluation
}

\author{
${ }^{*}$ Dr. R. K. Shah, Dr. A. B. Upadhyaya, Dr. L. P. Tibrewala, Dr. P. R. \\ Regmi, Dr. K. P. Acharya, Dr. H. H. Khanal
}

\section{Background:}

The pattern of cardiac disease differs from one region of the world to that of another'. Rheumatic heart disease Is still widely prevalent in $\mathrm{Nepal}^{2}$. The patterns and natural history is considerably different from what is seen in developed countries ${ }^{3}$, Few studies had been done in Nepal to address pattern of heart diseases ${ }^{4}$. Need of a large study to fill the gap and to show the profile of heart disease is there. This paper aims at providing the profile of heart disease as seen in Bir Hospital.

\section{Materials and Methods:}

\section{Study Population:}

Total number of cases was 11,290, Data analysis done among 10,436. Cases Patients having heart disease were 8654 while normal echocardiograms were 1782. Further analysis done among disease cases $(\mathrm{N}=8654)$.

\section{Exclusion Criteria:}

Patients having trivial mitral regurgitation, grade I. Aortic regurgitation, degenerative valvular lesions and other non Rheumatic valvular lesion, were not included in this study.

\section{Place}

Cardiac unit, Bir Hospital Kathmandu, Nepal.

\section{Period:}

March 1986 to Feb. 2001

Address for Correspondence: Dr. R. K, Shah, Cardiac Unit, Bir Hospital, Kathmandu, Nepal, G.PO. Box 801 I, Tal-528871 (Res.) Email:rkshah40@hotmail.com / rkshahdo @ yahoo.com Fax: 977:1-227374 


\section{Result:}

\section{Echocardiography profile of Heart disease}

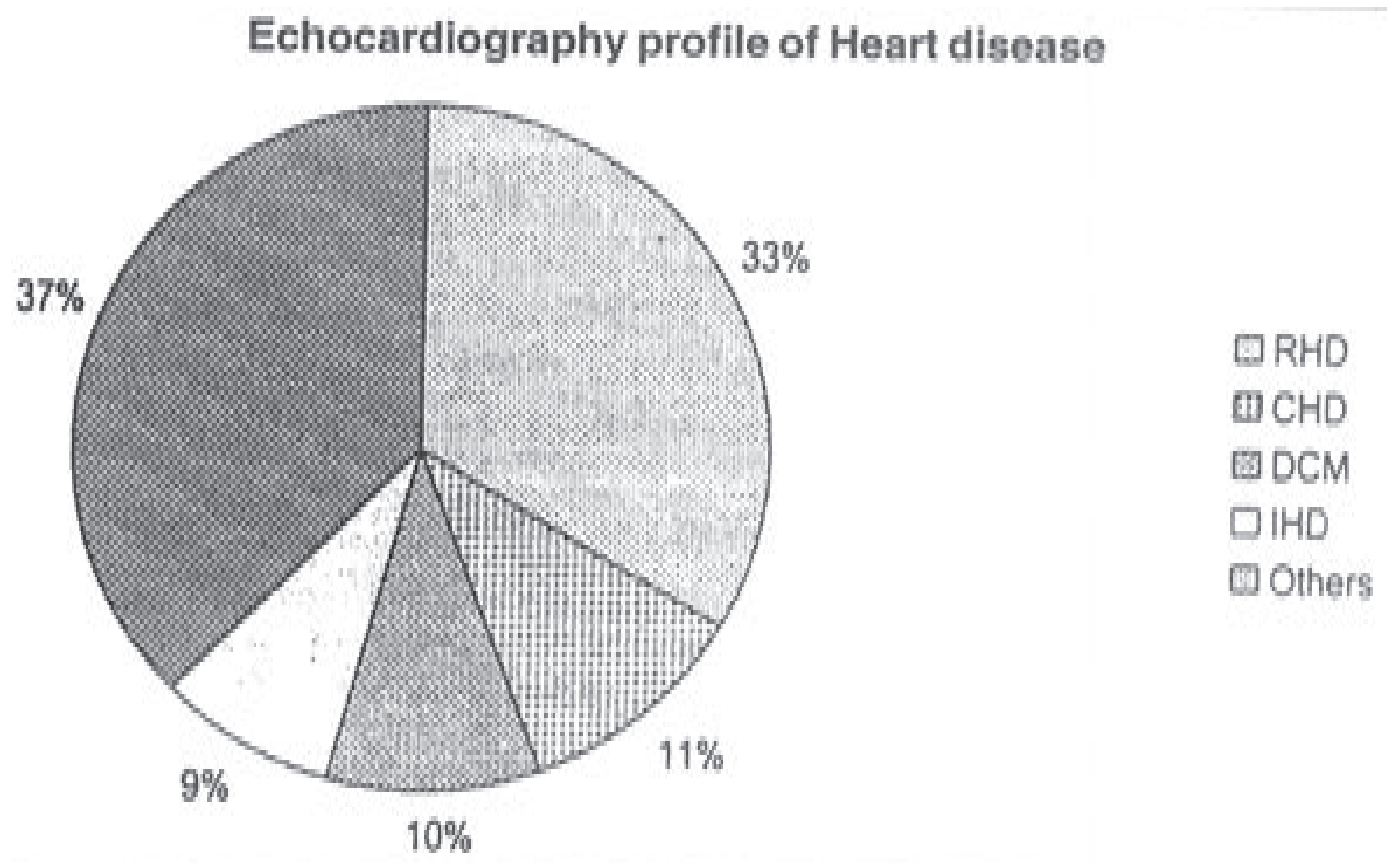

\section{Rheumatic Heart disease (RHD)}

Patiant having rheumatic heart disease were 2890 (33.4\%). Male cases were 1226 $(42.4 \%)$ and female were 1664 (57.6\%), Male and female ratio was 1:1.36. and age ranges from 7 year to 72 years. Mean age of male cases was 29.2 years, female was 30.6 years and combined mean was 29.9 years.

Mitral Valve Lesion Profile in Male, Female and Combined

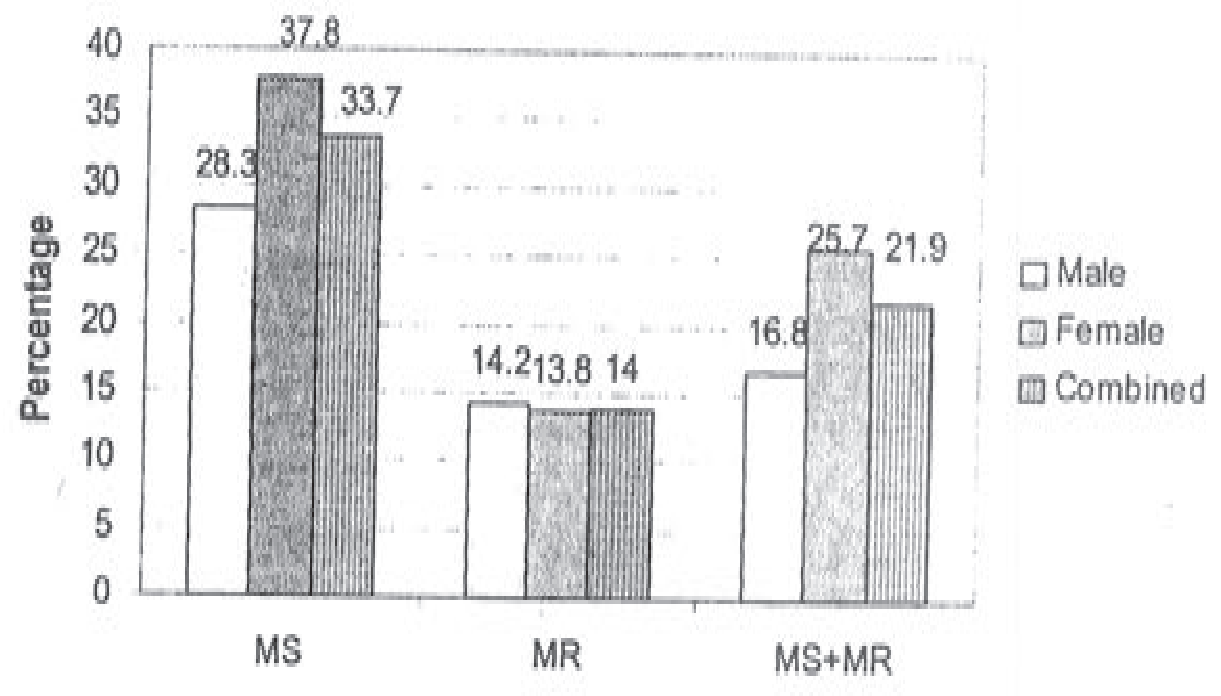


- NEPALESE HEART JOURNAL •

\section{Mitral valve Lesion Profile}

\begin{tabular}{|l|l|l|l|}
\hline Lesion & Males N=1226 & Females N=1664 & \multicolumn{1}{c|}{ Combined N=2890 } \\
\hline MS & $347(28.3 \%)$ & $628(37.8 \%)$ & $976(33.7 \%)$ \\
\hline MR & $174(14.2 \%)$ & $230(13.8 \%)$ & $404(14.0 \%)$ \\
\hline MS+MR & $206(16.8 \%)$ & $428(25.7 \%)$ & $634(21.9 \%)$ \\
\hline
\end{tabular}

Aorte Valve Lossion Profle in Male and Fomale

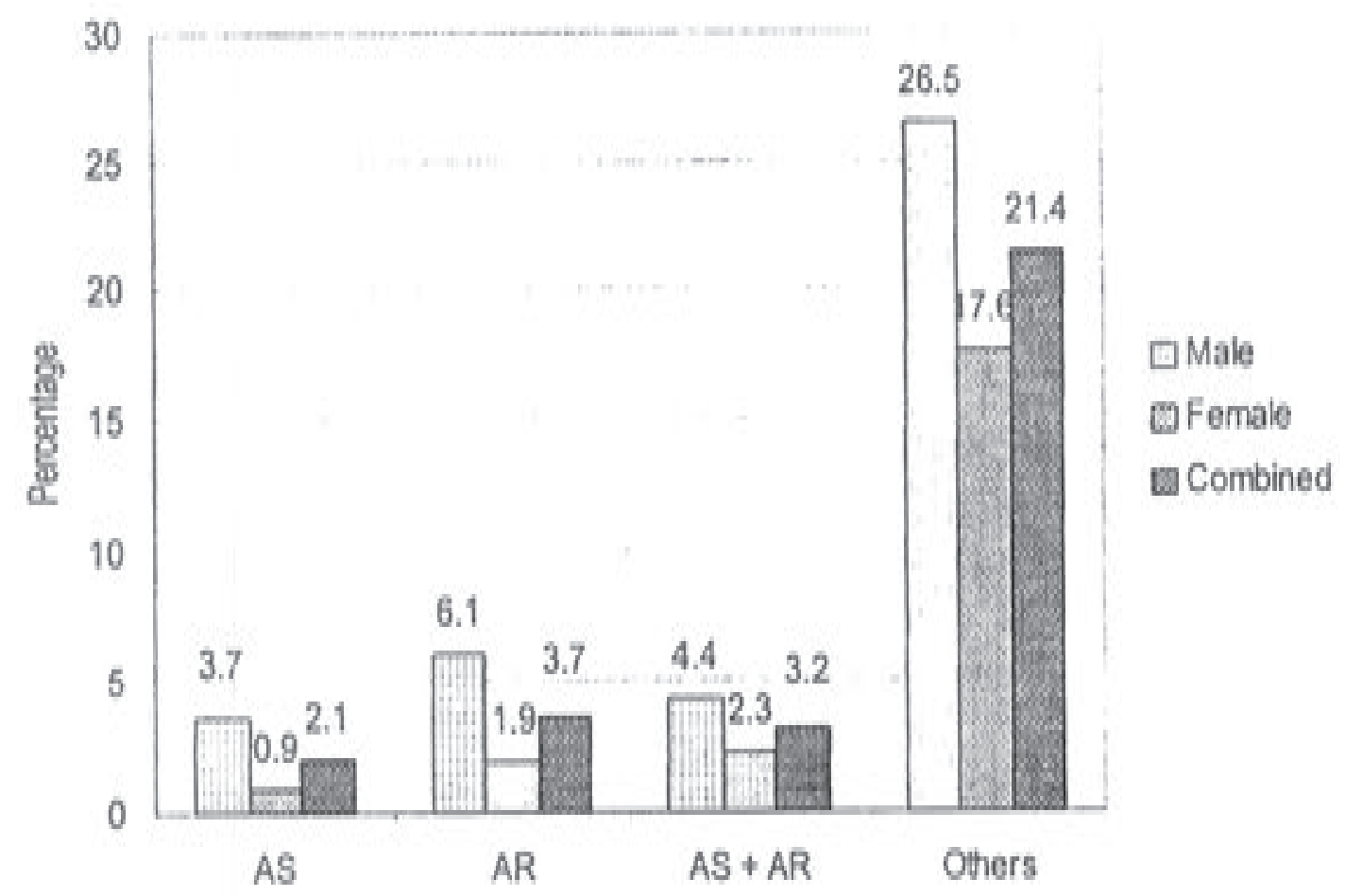

\section{Aortc Valve Lesion Profile}

\begin{tabular}{|l|l|l|l|}
\hline Lesion & Males N=1226 & Females N=1664 & Combined N=2890 \\
AS & $45(3.7 \%)$ & $15(0.9 \%)$ & $60(2.1 \%)$ \\
\hline AR & $75(6.1 \%)$ & $31(1.9 \%)$ & $106(3.7 \%)$ \\
\hline AS+AR & $54(4.4 \%)$ & $38(2.3 \%)$ & $92(3.2 \%)$ \\
\hline Others & $325(26.5 \%)$ & $293(17.6 \%)$ & $618(21.4 \%)$ \\
\hline
\end{tabular}


- NEPALESE HEART JOURNAL

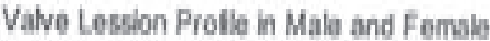

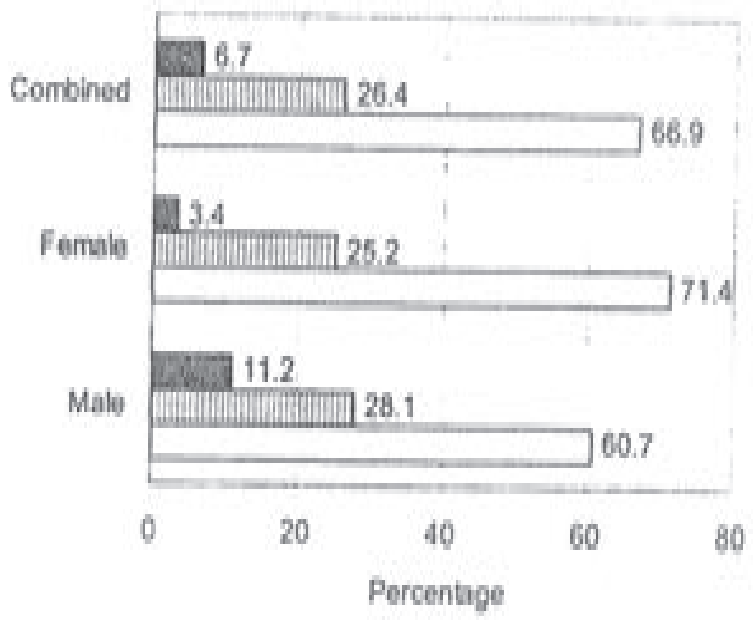

mothert

пD Double Vawa

口 bingle Vawe

\section{Valve Lesion Profile}

\begin{tabular}{|l|l|l|l|}
\hline Lesion & \multicolumn{1}{c}{ Males N=1226 } & \multicolumn{1}{l|}{ Females N=1664 } & \multicolumn{1}{l|}{ Combined N=2890 } \\
\hline Single Valve & $745(60.7 \%)$ & $1189(71.4 \%)$ & $1934(66.9 \%)$ \\
\hline Double Valve & $344(28.1 \%)$ & $419(25.2 \%)$ & $763(26.4 \%)$ \\
\hline Others & $137(11.2 \%)$ & $56(3.4 \%)$ & $193(6.7 \%)$ \\
\hline
\end{tabular}

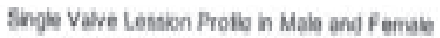

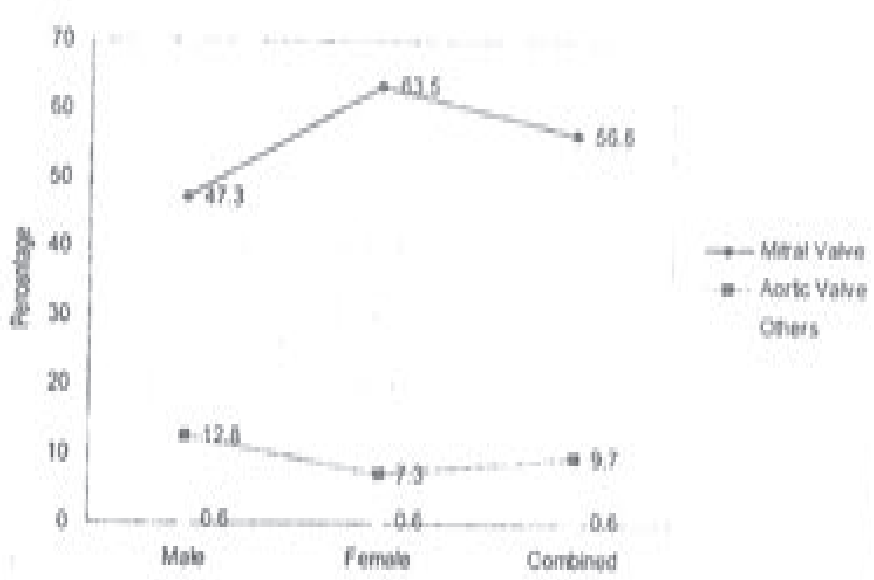

\section{Single valve Lesion Profile}

\begin{tabular}{|l|l|l|l|}
\hline Lesion & Males N=1226 & Females N=1664 & \multicolumn{1}{c|}{ Combined N=2890 } \\
\hline Mitral Valve & $580(47.3 \%)$ & $1056(63.5 \%)$ & $1636(56.6 \%)$ \\
\hline Aortic Valve & $158(12.8 \%)$ & $123(7.3 \%)$ & $281(9.7 \%)$ \\
\hline Others & $7(0.6 \%)$ & $10(0.6 \%)$ & $17(0.6 \%)$ \\
\hline
\end{tabular}


- NEPALESE HEART JOURNAL •

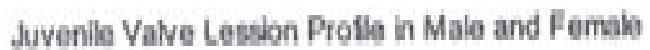

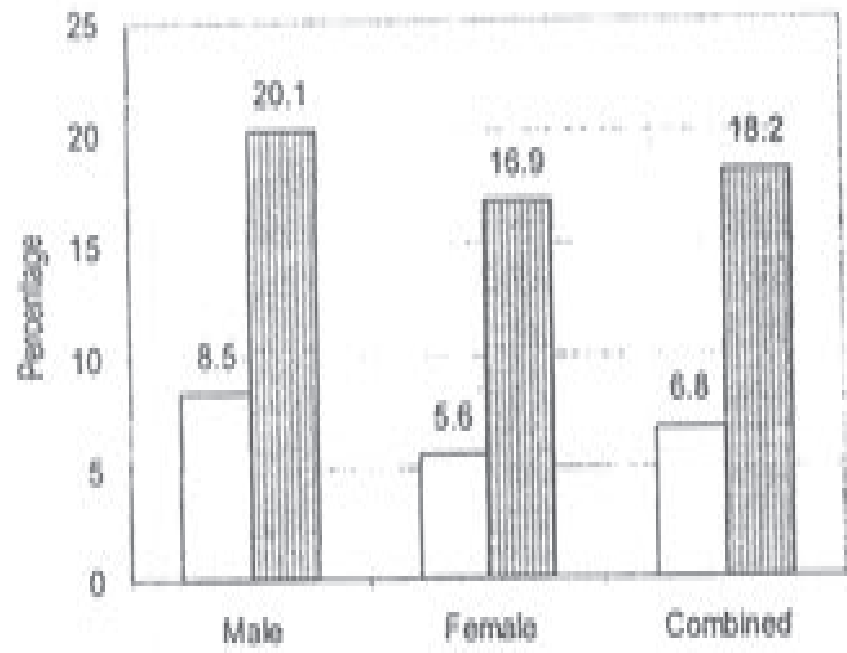

D Juvonib Miral Shnots

回 Juvenib Rhaumike heart dinhth

\section{Juvenile valve Lesion Profile}

\begin{tabular}{|l|l|l|l|}
\hline Lesion & Males N=1226 & Females N=1664 & Combined N=2890 \\
\hline $\begin{array}{l}\text { Juvenile Mitral } \\
\text { Stenosis }\end{array}$ & $104(8.5 \%)$ & $93(5.6 \%)$ & $197(6.8 \%)$ \\
\hline $\begin{array}{l}\text { Juvenile } \\
\text { Rheumatic } \\
\text { heart Disease }\end{array}$ & $246(20.1 \%)$ & $281(16.9 \%)$ & $527(18.2 \%)$ \\
\hline
\end{tabular}

\section{Discussion:}

Total cases of rheumatic heart disease were 2890 (33.4\%). Pure Mitral Stenosis was most common valvular lesion 976 (33.7\%).Cases of AR 106 (3.7\%) was more than AS 60 (2.1\%). Percentage of MS in Female 629 (37.8) was higher than in Male 347 (28.3\%), Pure AS and pure AR were dominant lesion in male. [45 (3.7) and 75 (6.1\%)] than in female [15 (0.9\%) and $31(1.9 \%)]$ respectively.

Combined MS and MR were also dominant lesion in female 428 (21.9\%) than in male 206 (16.8\%). But mixed AS and AR was commoner in male 54 (4.4\%) than in Female $38(2.3 \%)$. Cases of single valve (67.6\%) lesion were more than double valve $(26.4 \%)$. Single valve lesion was dominant in Female $(72.1 \%$ versus $61.6 \%)$ while double valve lesion was dominant in male (28.1\% versus 25.2\%). Juvenile Ms was 197 (6.8\%) and Juvenile RHD 527 (18.2\%). 
One study done in Bangalore 5, India where patients having mitral stenosis alone was less than this study (14.3\% versus $33.7 \%$ ) while mixed mitral stenosis and mitral Regurgitation was more $(24.8 \%$ versus $21.9 \%)$, patients having involvement of both mitral and Aortic valves were more (40.3\%) versus $26.4 \%)$. Study in an out patients cardiac clinic, Addis ababa shows patients having rheumatic heart disease were more (159.4\% versus $33.7 \%)$ and patients with congenital heart disease were also more (35.9 verses $10,8 \%$ ), Lowest age of presentation of rheumatic heart disease was 7 year while a study done in the outpatient department of the National Center for control of rheumatic fever and heart diseases Dhaka. Lowest age was 5 years.

\section{Conclusion:}

Rheumatic Heart disease is most common heart diseases (33.4 percent), Females outnumbered males $(1.36: 1)$ Commonest valvular lesion is mitral stenosis (33.7 percent) Juvenile mitral stenosis is common (6.8 percent) and Juvenile RHD ( 18.2 percent) Single valve lesion is 2.5 times commoner (66.9 percent) than double valve ( 26.4 percent).

\section{Acknowledgment:}

This paper was originally presented at bimonthly meeting of cardiac society of Nepal and National seminar on prevention of heart disease in Nepal, held in Kathmandu, 2001. The authors express their appreciation and gratitude to Dr. M.A. Pandey, Dr, D.B. Karki, Dr. M. R. Bajracharya, DR. T.N. Bhattarai, for their contribution to cardiac unit, Bir Hospital. Special thanks to Mrs, Srijana and Mr, Krishna Chadra Shab for their assistance in preparing and shaping out this article,

\section{References}

1. Daniel - E ; Abegaz B profile of cardiac disease in an out patient cardiac clinic. TropGeogr-mead. 1993; 45(3): 121-3

2. Regmi PR, Pandey MR Prevalence of rheumatic fever and rheumatic heart disease in school children of kathmandu city, indian - Heart- J 1997 sep-oct; 49 (5); 518-20

3. Rao DR; Changing Pattern of rheumatic heart disease In india in Panja M, editor, medicine update, APICON 2001 679-82. 
4. Shrestha UK; Bhattarai TN; Pandey MR Prevalence of rheumatic fever and rheumatic heart disease in school children in a rural community of the hill region of NEPAL indian-Heart-|. 1991 Jan Feb 43 (1): 39-41

5. Sridhar L; Ramamurthy B; Yavagal ST et al Pattern and prevalence of Rheumatic Heart disease by echocardiographic evaluation, Indian Heart j 2000 Nov dec.52 (6): 673

6. Zaman -MM; Rouf MA; Haque-S; et al does rheumatic fever occur usually between the ages of 5 and 15 years? Int j -cardiol. 1998 sep 1: 66 (1); 17-21

Address for Correspondence: Dr. R. K, Shah, Cardiac Unit, Bir Hospital, Kathmandu, Nepal, G.PO. Box 801 |, Tal-528871 (Res.) Email:rkshah40@hotmail.com Arkshahdo @ yahoo.com Fax: 977:1-227374 